\title{
Is Soccer Played Fairly?
}

Neil Edmund Roy, Roberto Ayala \& Azizur Khan

\section{Introduction}

Club soccer today is bigger than it has ever been. The passion people have for their respective clubs can almost certainly be paralleled to that of their national teams. As a sport soccer goes above and beyond the theatrics witnessed on the field. The mechanics involved behind the scenes more often than not determine a club's success, or lack of it. It is an international sport that elicits passion and pride among supporters culminating into a multimillion dollar business. And like any other firm in a market a club aims to maximise profits at the lowest possible costs.

An unavoidable result of the manner in which the soccer market operates is the rather evident disparity that exists amongst soccer clubs today. We have grown accustomed to viewing soccer in an environment tainted with disparity. Over the years, we have been desensitised to how bigger clubs such as Real Madrid and Manchester United seem to only grow bigger. While smaller clubs such as, Xerez and Portsmouth, have to contend with comparatively trivial issues pertaining to merely surviving.

\section{Factors that contribute to the Disparity}

The 'haves' and the 'have nots' in terms of resources, are labels that hold just as true in soccer as in any other economic environment. A natural question to ask would be what factors contributed to this disparity that is so apparent in soccer today. We will attempt to highlight some of these factors by analysing what clubs' and players' strive to achieve through their respective utility functions. 
Applying economic theory, we could customize the soccer club's and players' utility functions as follows:

$$
\mathrm{U}=\mathrm{f}\left(\mathrm{X}^{1}+\mathrm{X}^{2}+\mathrm{X}^{3} \ldots . . . \mathrm{X}^{\mathrm{n}}\right)
$$

where $U$ is the benefit pursued (objective-attainment) and the $X^{i}$ are factors or motivators that help achieve that benefit

\section{An Analysis of the Clubs' Utility Function}

Several factors arguably motivate soccer clubs to maximize their utility on the field and on the business front as well. On the field they are primarily concerned with seeking recognition as a successful club, which consequently allows them to gain power and influence within the league that they compete as well as within their followers. On the business front soccer clubs are interested in developing a meaningful brand image through media coverage enabling more brand-loyal customers and a larger spectator base. This assists the club to enjoy economies of scale in production on and off the field, and attaining their main goal of profit maximization.

For the sake of exposition we could populate the club's utility function as follows:

$\mathrm{U}$ (Profit Maximisation) =Revenues (merchandising and sponsorship, match-day gate revenue, Broadcasting TV) - Costs (high talent, effective team management, team infrastructure)

NOTE: economies of scale is a result of growth but not a direct objective

Obviously soccer clubs would follow a causal logic chain that combines the above factors in order to achieve the maximum benefit possible. For instance, clubs recognise that their stock of high-talent players would increase their costs but would normally contribute more at the margin towards better team performance and an increase in their supporter base, culminating with an increase in the club's net profit. Therefore, a club's talent and its 
management team in effect are the assets it purchases towards achieving successful outcomes, victories and championships. Such outcomes are usually the only way to gain a large fan base. This then transforms a soccer club into an attractive investment, attracting sponsorships, broadcasting TV rights as well as an increase in gate revenue.

As a result, soccer clubs now operate as rational firms that hire productive resources and organize them to produce and sell a particular product (performance and entertainment) in the pursuit of profit maximisation. Such products are traded in a market of monopolistic competition, where a club's brand image differentiates it from its rivals and creates brand loyal customers. As clubs grow in size they benefit from further economies of scale emerges as a key factor that leads to the efficient use of resources. Therefore, a larger stadium and a higher attendance coupled with a wider media and broadcasting coverage of soccer games would arguably facilitate the production of the club's product at a lower average cost.

However, the process described above seems to indicate that the above objectives are likely to only be achievable by a few soccer clubs that do attain success and are able to capitalize on that success with increasing returns enabling further economies of scale. For smaller clubs accessing such increasing returns that accompanies success is harder and they seem to be trapped in a situation where they simply cannot benefit from economies of scale. As a result the extant gap between the rich and poor clubs only seems to get bigger and more evident. Success is reserved just for those clubs that can invest vast amounts of capital in key resources that maximizes their potential to remain successful.

\section{Talent price and the Soccer Transfer Market (STM)}

In our view, the market characteristics of soccer clubs to some extent serve to increase this inequality. Consider, for instance, the Soccer Transfer Market (STM). Under the STM rules, soccer clubs buy and sell players by paying transfer fees that may even equal the GDP of certain small nations. The STM in effect allows certain clubs to flex their financial muscles. In 2009, Real Madrid made history in the STM by spending GBP136 million for Kaka and 
Cristiano Rolando. This amount was approximately equivalent to the GDP generated by Tonga and Dominica in that year. (CIA, 2009).

How is it possible for a club to pay such an exorbitant sum of money for a soccer player? Certain clubs, such as Madrid, that value these exceptionally talented players, are willing to pay substantial transfer fees to employ their services. The more bargaining power a buying or selling club has, the more likely it is for them to negotiate mutually higher prices.

Figure 1 (Adapted from McTaggart D., Findlay C., Parkin M., 2007)

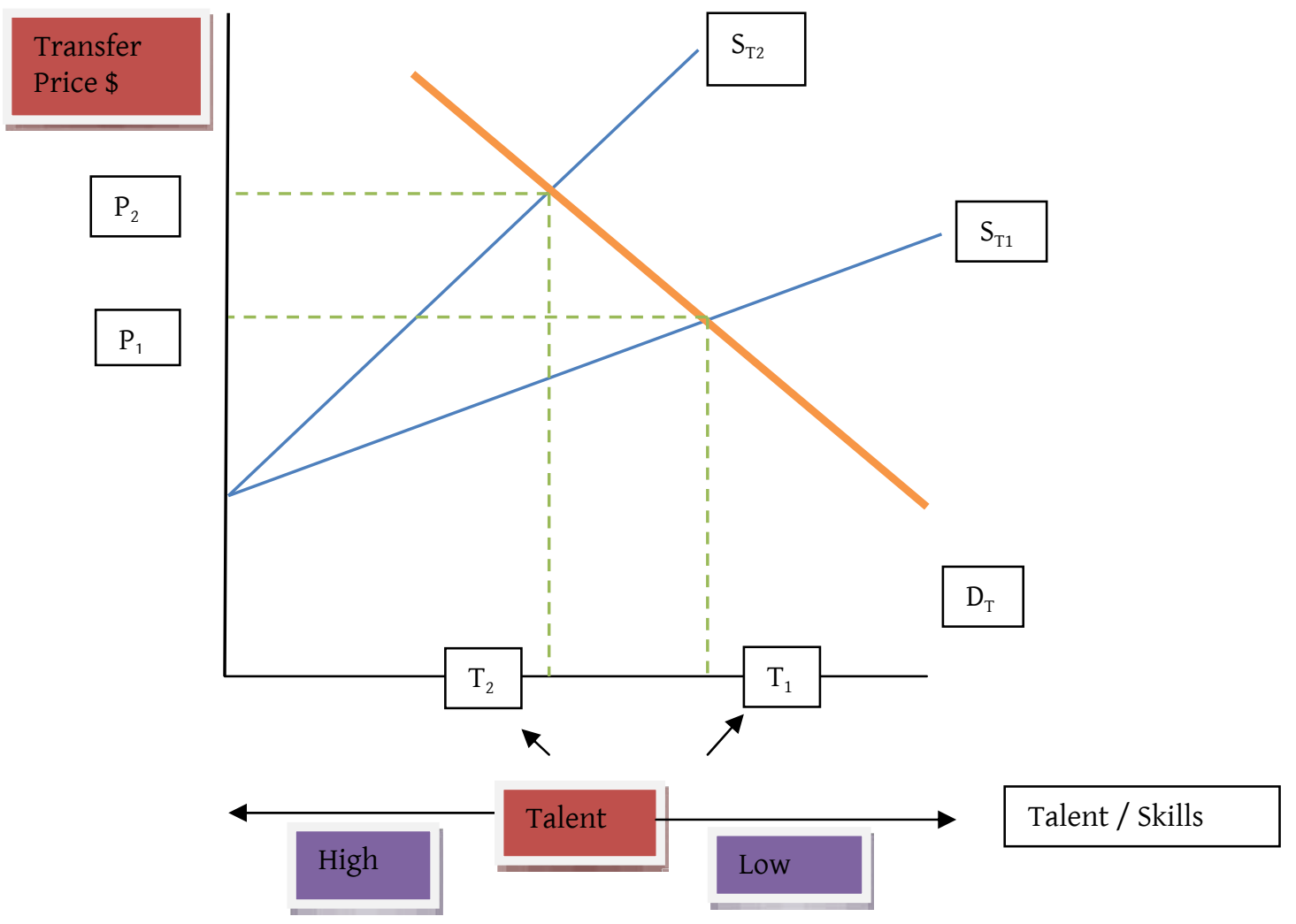

Roy et. al. 
The figure above illustrates what happens in such an environment. Highly talented players, or "superstars", are a scarce resource. Lower talent is not even considered a close substitute $\left(\mathrm{T}_{1}\right)$. Since talent is accumulated with increasing returns, the real and time cost of developing further skills to match those of a superstar is prohibitively expensive for lower talented players making the acquisition of the expertise and skill that the superstar already has a relative bargain. Based on these factors, the supply curve for superstars becomes less elastic, which means irrespective of the price, the quantity supplied tends to remain fixed. As a result, the player's price is magnified $\left(\mathrm{P}_{2}\right)$ as his demand is concentrated to the few clubs that can afford it.

\section{An Analysis of the Players' Utility Function}

What attracts a player to soccer in the first place? At the core is his primal love of the game. He grows up in a soccer influenced environment where he aspires to be the best. He would be exposed to the potential fame and fortune the game promises - the result of the phenomenal media coverage the game has always enjoyed. He would have had his favourites, and would have grown up idolizing them; hoping to someday parallel or maybe even surpass their achievements.

Consequently, a player's utility function can be described as a positive function of success - be it recognition or career income as well as the joy of playing and a negative function of the costs or sacrifices he must make to achieve success the game, which could arguably be lower for a superstar player due to his innate skills.

$\mathrm{U}($ Fame \& Fortune $)=\mathrm{f}$ (professional success, joy of playing $)-\mathrm{c}$ (sacrifices such as time, effort to acquire skills, family life, etc.)

Herein lies another reason for what may drive disparity in soccer.

While it may be true that the interface between clubs and highly talent players occurs on the basis of the rational pursuit of utility, the history, tradition and overall reputation of 
clubs matters a lot. Consider that the favourite former players of any new player would have at some point in their careers represented some top-tier club. In fact, it is when they were most likely to have attracted the admiration of the youngsters in question. In such a scenario, a self-selection process may arise whereby the next generation of aspiring soccer players would want to replicate the success of their idols by wishing to play at the same big clubs they played at. It makes for a rather interesting self-sustaining situation since these bigger clubs, are almost always guaranteed premier talent. This is of course assuming that the clubs have managed their finances well, allowing them to remunerate the services of these potential superstars.

\section{Intervention}

Recent decades have seen notable changes in the market for soccer. The most significant was the Bosman Ruling implemented in 1995, which removed restrictions in the European labour market for soccer talent, and the introduction of the Champions' League in its new format. (Haan, et. al., 2000)

Now, the Champions League single-handedly is not the setback either, but it's an outstanding example and a homespun one by UEFA at the same time. So we will stick to it for our purpose. The difficulty in broad spectrum is unequal booty for success. The upshot was that more clubs could benefit from a portion of the participating proceeds from the competition. This was done to regulate to promotion of a wider distribution of wealth.

Another such intervention is to be instituted by European soccer's governing body UEFA (Union of European Football Association) through 'Financial Fair Play'.

Currently, the major clubs' have asymmetrical access to external finance compared to smaller clubs owing to their brand name. Smaller clubs have to be content with operating from whatever little revenue they can generate internally. UEFA wants to introduce the concept of 'Financial Fair Play' by 2012 as a precondition to participating in the most lucrative club competition - the Champions' League. Clubs will have to adjust their accounts and function within their financial means, presumably making the European 
game more equitable and stable since they believe that the current levels of transfer fees cannot be sustained.

\section{Consequences}

Even though this intervention institutes penalties for those soccer teams that do not meet the new rule, it perhaps does not attack the root of the issue. The ex ante status quo would very likely still remain and the big clubs will surely remain the big clubs ex post as well. As such, competitive rights for being the best and most affluent of the clubs, would only be the reserve of major clubs following these guidelines.

The latest English club to break through the elite circle of Arsenal, Manchester and Liverpool was Chelsea, a very unsustainable club that injected hundreds of millions into transfers and wages to play regularly at Champions League football and a shot at winning a big trophy in return. The new laws rule this out even as a possibility making Europe's domestic leagues even more likely to resist changes in the hierarchies, than they already are.

The tagline of spending "within financial means" focuses on promoting the idea of expenditures being derived from revenue generated through soccer alone. This will arguably reinforce the status quo inequality across clubs. Clubs based in bigger cities and clubs with a fan following across the globe have the ability to generate more soccer-related revenue. Financial fair play therefore does not seem to be capable of stemming the problems of the inequality across clubs and the diminishing aspirations among prospective upcoming clubs and players. It may further even divert interest away from soccer towards other more lucrative sports.

On a global level, while there have always been larger and smaller clubs. However, the globalization of soccer has made quite a few clubs bigger. Unfortunately, an even larger number of smaller clubs failed to benefit from this, thereby creating a disparity between the 'haves' and the 'have nots' of soccer clubs. This disparity is a glaring and embarrassing "own goal" in the game of soccer. 


\section{References}

- Francka, Egon and Nescha, Stephan (2008) "Mechanisms of Superstar Formation in German Soccer: Empirical Evidence”, European Sport Management Quarterly, Volumer 8, Issue 2, pp. 145-164.

- Central Intelligence Agency (2009) The World Factbook, CIA, retrieved 20 April 2010, <https://www.cia.gov/library/publications/the-world-factbook/geos/us.html>.

- Haan, M; Koning, R and Arjen, W (2000) "Market Forces in European Soccer", retrieved on $16^{\text {th }}$ April $2010<w w w . r h k o n i n g . n l>$.

- Martin M (2005) "Globalization and Sport in Historical Context University of California, San Diego, retrieved on $20^{\text {th }}$ April 2010 $<$ http://www.la84foundation.org/SportsLibrary/UCSD/UCSDMartin.pdf >.

- McTaggart D., Findlay C., Parkin M. (2007) Economics, Pearson Education Australia , $5^{\text {th }}$ Editionб, New South Wales. 